\title{
Cancer Site and Adverse Events Induced by Immune Checkpoint Inhibitors: A Retrospective Analysis of Real-life Experience at a Single Institution
}

\author{
AMMAR SUKARI ${ }^{1}$, MISAKO NAGASAKA ${ }^{1,2}$, ROBA ALHASAN $^{3}$, DHAVAL PATEL $^{1}$, ANTOINETTE WOZNIAK $^{4}$, \\ RADHAKRISHNAN RAMCHANDREN ${ }^{1}$, ULKA VAISHAMPAYAN ${ }^{1}$, AMY WEISE $^{1}$, \\ LAWRENCE FLAHERTY ${ }^{1}$, HYEJEONG JANG ${ }^{1}$, SEONGHO KIM ${ }^{1}$ and SHIRISH GADGEEL ${ }^{5}$ \\ ${ }^{1}$ Department of Oncology, Barbara Ann Karmanos Cancer Institute, \\ Wayne State University School of Medicine, Detroit, MI, U.S.A.; \\ ${ }^{2}$ Department of Advanced Medical Innovation, \\ St. Marianna University Graduate School of Medicine, Kawasaki, Japan; \\ ${ }^{3}$ Department of Hematology and Oncology, Michigan State University, Lansing, MI, U.S.A.; \\ ${ }^{4}$ Department of Oncology, University of Pittsburgh, Pittsburgh, PA, U.S.A.; \\ ${ }^{5}$ Department of Internal Medicine, Division of Hematology/Oncology, \\ University of Michigan, Ann Arbor, MI, U.S.A.
}

\begin{abstract}
Background: Data on the characteristics of patients who are likely to experience adverse events, both immunerelated and non-immune-related, from programmed cell death1 (PD1) inhibitors are limited. Patients and Methods: Data from patients who received $\geq 1$ dose of single-agent $P D 1$ inhibitor between August 3, 2011 and August 31, 2016 were obtained from our Institution's pharmacy database. AEs were graded using Common Terminology Criteria for Adverse Events version 4. Results: One hundred and eighty-two patients received at least one dose of single-agent PDI inhibitor prior to data cut-off. After excluding 14 patients with uncommon malignancies, the total number of patients were 168. The median age was 63 (range $=24-92$ ) years. There were $87(52 \%)$ cases of non-small cell lung cancer (NSCLC), 35 (21\%) of renal cell carcinoma (RCC), 12 (7\%) of melanoma, $18(11 \%)$ of Hodgkin's lymphomas, eight (5\%) of head and neck squamous cell carcinoma (HNSCC) and eight (5\%) of small cell lung cancer. Considering grade 2 or more AEs, 30 (18\%) patients had kidney injury, 34 (20\%) hypothyroidism, 36 (21\%)
\end{abstract}

This article is freely accessible online.

Correspondence to: Ammar Sukari, MD, Department of Oncology, Barbara Ann Karmanos Cancer Institute, Wayne State University School of Medicine, 4100 John R Detroit, MI 48201, U.S.A. Tel: +13135768778, e-mail: sukaria@karmanos.org

Key Words: Immunotherapy, PD1 inhibitor, primary tumor, immune related toxicities, immune-related side-effects, hypothyroidism, pneumonitis, renal insufficiency. transaminitis, 20 (12\%) pneumonitis, and 18 (11\%) colitis. Patients with RCC had higher odds of experiencing grade 2 or more kidney injury than patients with other primary tumor types (adjusted $p=0.025$ ), whereas patients with Hodgkin's lymphoma and HNSCC had higher odds of grade 2 hypothyroidism (adjusted $p=0.005$ ). Patients with NSCLC had higher risk of death with pneumonitis than those whose primary cancer was not NSCLC (adjusted $p=0.005$ ). Discussion: The increased odds of patients with Hodgkin's lymphoma and HNSCC experiencing grade 2 or more hypothyroidism may be related to previous radiation exposure. Most patients with RCC had undergone nephrectomy, making them more susceptible to acute kidney injury. When pneumonitis occurred in patients with primary NSCLC, the overall survival was significantly worse. The duration of PDI therapy was significantly associated with onset of pneumonitis $(p=0.007)$. Conclusion: The site of primary tumor or metastasis may help predict the most common AEs in patients treated with PDI inhibitors.

Immunotherapy targeting checkpoint programmed cell death protein 1 (PD1) and its ligand PD-L1 has advanced the treatment of many tumor types, including melanoma $(1,2)$, nonsmall cell lung cancer (NSCLC) (3-5), head and neck squamous cell carcinoma (HNSCC) (6), renal cell carcinoma (RCC) (7), urothelial cancer (8) and Hodgkin's lymphoma (HL) (9).

Nivolumab and pembrolizumab are human and humanized monoclonal antibodies that block the interaction of PD1 with its ligands, PD-L1 and PD-L2. PD1 inhibitors work by reinstating the natural anticancer immune-mediated cytotoxicity $(10,11)$. The PD1/PD-L1 pathway acts as a self-tolerance pathway to prevent unchecked immune response toward 
normal tissue. With the development of agents that block this pathway, some degree of autoimmune events from hyperactivated T-cell responses is expected. The most widely known immune-related adverse events are those involving major organs, such as the lungs, liver, or kidneys, but theoretically, immune-related AEs may develop in any tissue (12).

Data on the characteristics of patients who are more likely to experience these immune-related AEs are limited.

We conducted a retrospective assessment of patients with advanced cancer treated with these agents to assess the risk of potential immune-related AEs.

\section{Patients and Methods}

This study was approved by the Wayne State University Institutional Review Board (approval \#062616M1E). Data from patients who received at least one dose of single-agent PD1 inhibitor from August 3, 2011 to August 31, 2016, were obtained from our Institution's pharmacy database. August 3, 2011 was the first date a patient had a PD1 inhibitor administered on a trial, which provided us approximately 5 years of treatment data. The Institution's pharmacy database was reviewed to identify order data, and then, the nursing database was used to validate the administration of a drug on a certain date. Our study focused on five AEs, namely kidney injury, hypothyroidism, transaminitis, pneumonitis, and colitis/diarrhea, as these could potentially be immune-related. Patients were considered to have had these AEs if these were documented on any day after the first dose of PD1 inhibitor administration. Data on the dates of occurrence, grades (the highest grade was attributed to continuously worsening events), and the use of steroids (yes/no) were obtained from electronic records. Electronic records of all of the patients were carefully reviewed. Kidney injury (creatinine), hypothyroidism, thyroid-stimulating hormone and transaminitis [elevated aspartate aminotransferase/alanine amino transferase], and elevated alkaline phosphatase were documented based on laboratory values. Pneumonitis, colitis and diarrhea were captured based on documentation by the treating physicians. Events of pneumonitis were also captured through radiology reports of computed tomographic scans. Even if the term pneumonitis was not documented in the electronic chart, when findings consistent with pneumonitis were found on imaging reports and the treating physician mentioned the possibility of an "immune-response" or "inflammatory-response", these events were categorized under pneumonitis. Similarly, those with abdominal symptoms who underwent colonoscopy and were found to have findings consistent with colitis were grouped under colitis, even if the treating physician did not use the term colitis. AEs of kidney injury (under investigations category, creatinine increased section), hypothyroidism (under endocrine disorders section), transaminitis (under investigations category, from sections: alanine aminotransferase increased, alkaline phosphatase increased, and aspartate aminotransferase increased), pneumonitis (under respiratory, thoracic, and mediastinal disorders) and colitis/diarrhea (under gastrointestinal disorders) were recorded and graded based on Common Terminology Criteria for Adverse Events (CTCAE) version 4 (13) independently by the study investigators.

Baseline patient characteristics were summarized using count and percentage for categorical variables, and median and range for continuous variables and further were statistically compared between those treated on a clinical study $v s$. those treated off of a clinical study (on vs. off study) by Fisher's exact test for categorical variables and Kruskal-Wallis test for continuous variables. Overall survival (OS) was defined as the time from the date of treatment to death from any cause. Patients who were alive were considered censored at the date of last observation. Kaplan-Meier estimates were used to summarize the distribution of OS. Univariable and multivariable logistic regression models were fit to assess associations between toxicities (grade 0-1 vs. $\geq 2$ ) and prior chosen predictors (age at treatment, primary tumor, steroid use and clinical trial status). Univariable and multivariable Cox proportional hazards regression models were fit to assess associations between prior chosen predictors (age at treatment, primary tumor, toxicity, steroid use and clinical trial status) and survival benefit (OS). The proportional hazards assumption was assessed and no violation was found.

\section{Results}

One hundred and eighty-two patients received at least one dose of single-agent PD1 inhibitor prior to data cut-off. After excluding 14 patients with uncommon malignancies (four urothelial, three colonic, two nasopharyngeal, one anal, three esophageal/gastric/gastroesophageal junction and one mesothelioma), the total number of patients was 168 . Baseline patient characteristics are summarized in Table I. The median age was 63 (range $=24-92$ ) years. There were 87 $(52 \%)$ NSCLC cases, $35(21 \%)$ of RCC, 12 (7\%) of melanoma, $18(11 \%)$ of HL, eight (5\%) of HNSCC cases and eight $(5 \%)$ of small-cell lung cancer. The majority of patients received single-agent nivolumab $(n=124,74 \%), 44(26 \%)$ patients received pembrolizumab.

Groups 1 and 2 hereafter represent patients who experienced no more than grade 1 AEs and those who experienced at least one grade $2 \mathrm{AE}$, respectively, among five potentially immune-related AEs. The median age was 61 (range $=25-88)$ years for group $1(\mathrm{n}=67)$ and 65 (range $=24$ 92) years for group $2(\mathrm{n}=101)$. In group 2, $20(20 \%)$ patients were hospitalized for AEs and 54 (53\%) were treated with steroids, both of which were statistically significant when compared to group 1 (Table I).

Table II shows the numbers of toxicities by grade based on CTCAE v4. There were no grade 5 events. In total, grade 2 or more events were kidney injury in $30(18 \%)$, hypothyroidism in $34(20 \%)$, transaminitis in $36(21 \%), 20$ (12\%) pneumonitis, and $18(11 \%)$ colitis. Grades 3 and 4 were rare, except for grade 3 colitis/diarrhea. There were no statistical differences in the toxicities experienced by patients on and off trial (supplementary data not shown, available upon request). Table III displays the univariate and multivariate logistic regression analyses of factors associated with grade 2 or more toxicity but focuses on the organs at risk. For example, analysis of kidney injury was performed on those with primary tumors (RCC/other) in addition to other factors of age, agent (single/combination), clinical trial status (on/off), and steroid use (yes/no). Table III shows the results of univariate and multivariate logistic regression 
Table I. Baseline patient characteristics overall and according to grade of immune-related adverse events (AEs). Groups 1 and 2 represent patients who experienced no more than grade 1 immune-related adverse events and those who experienced at least one grade 2 respectively.

\begin{tabular}{|c|c|c|c|c|c|}
\hline & & Group $1(n=67)$ & Group $2(\mathrm{n}=101)$ & $\operatorname{ALL~}(n=168)$ & $p$-Value \\
\hline Age, years & Median (range) & $61(25-88)$ & $65(24-92)$ & $63(24-92)$ & 0.779 \\
\hline \multirow[t]{2}{*}{ Gender, n (\%) } & Female & $28(42)$ & $37(37)$ & $65(39)$ & 0.521 \\
\hline & Male & $39(58)$ & $64(63)$ & $103(61)$ & \\
\hline \multirow[t]{2}{*}{ Agent, n (\%) } & Pembrolizumab & $16(24)$ & $28(28)$ & $44(26)$ & 0.597 \\
\hline & Nivolumab & $51(76)$ & $73(72)$ & $124(74)$ & \\
\hline \multirow[t]{2}{*}{ Clinical trial, n $(\%)$} & Off & $49(73)$ & $65(64)$ & $114(68)$ & 0.244 \\
\hline & On & $18(27)$ & $36(36)$ & $54(32)$ & \\
\hline \multirow{2}{*}{ Hospitalization within 6 weeks, n (\%) } & No & $56(84)$ & $78(77)$ & $134(80)$ & 0.335 \\
\hline & Yes & $11(16)$ & $23(23)$ & $34(20)$ & \\
\hline \multirow[t]{8}{*}{ Primary tumor, $\mathrm{n}(\%)$} & Melanoma & $6(9)$ & $6(6)$ & $12(7)$ & 0.706 \\
\hline & Lung Ad & $25(37)$ & $28(28)$ & $53(32)$ & \\
\hline & Lung SCC & $11(16)$ & $18(18)$ & $29(17)$ & \\
\hline & Lung Poorly diff. & $2(3)$ & $3(3)$ & $5(3)$ & \\
\hline & SCLC & $3(4)$ & $5(5)$ & $8(5)$ & \\
\hline & HNSCC & $1(1)$ & $7(7)$ & $8(5)$ & \\
\hline & $\mathrm{RCC}$ & $12(18)$ & $23(23)$ & $35(21)$ & \\
\hline & Hodgkin's lymphoma & $7(10)$ & $11(11)$ & $18(11)$ & \\
\hline \multirow[t]{3}{*}{ Hospitalization for AE, n (\%) } & No & $66(99)$ & $80(79)$ & $146(87)$ & $<0.001$ \\
\hline & Yes & $1(1)$ & $20(20)$ & $21(12)$ & \\
\hline & Missing data & $0(0)$ & $1(1)$ & $1(1)$ & \\
\hline \multirow{2}{*}{ Steroid use, n (\%) } & No & $44(66)$ & $47(47)$ & $91(54)$ & 0.018 \\
\hline & Yes & $23(34)$ & $54(53)$ & $77(46)$ & \\
\hline Duration of PD1 inhibitor, months & Median (95\% CI) & $4.82(3.7-8.03)$ & $3.44(2.3-6.62)$ & $4.44(3.41-6.2)$ & 0.640 \\
\hline
\end{tabular}

Ad, Adenocarcinoma; CI: confidence intervaI; SCC, squamous cell carcinoma; SCLC, small cell lung cancer; HNSCC, head and neck squamous cell carcinoma; RCC, renal cell carcinoma.

Table II. All toxicities by Common Terminology Criteria for Adverse Events grade (version 4) (13).

\begin{tabular}{|c|c|c|c|c|c|c|}
\hline \multirow[b]{2}{*}{ Toxicity } & \multicolumn{4}{|c|}{ Grade, number of events (\%) } & \multirow[b]{2}{*}{ Missing data } & \multirow[b]{2}{*}{ Total } \\
\hline & 1 & 2 & 3 & 4 & & \\
\hline Kidney injury & $52(31)$ & $28(17)$ & $1(1)$ & $1(1)$ & $3(2)$ & 168 \\
\hline Hypothyroidism & $19(11)$ & $34(20)$ & $0(0)$ & $0(0)$ & $21(12)$ & 168 \\
\hline Transaminitis & $74(44)$ & $18(11)$ & $15(9)$ & $3(2)$ & $4(2)$ & 168 \\
\hline Pneumonitis & $5(3)$ & $10(6)$ & $9(5)$ & $1(1)$ & $0(0)$ & 168 \\
\hline Colitis & $1(1)$ & $1(1)$ & $15(9)$ & $2(1)$ & $0(0)$ & 168 \\
\hline Diarrhea & $61(36)$ & $12(7)$ & $13(8)$ & $2(1)$ & $0(0)$ & 168 \\
\hline
\end{tabular}

analyses of factors associated with grade 2 or more toxicities with regards to pre-specified factors of age, lung disease, steroid use and clinical trial status, in relation to the primary tumor and organ at risk. Table IV describes Cox regression analyses of factors associated with OS. In this study, patients with primary NSCLC had worse OS. Table V shows the results of univariate and multivariate Cox regression analyses of factors associated with OS for toxicities with regards to pre-specified factors of age, NSCLC, steroid use, clinical trial status and toxicity grade, in relation to the primary tumor and organ at risk.
Renal insufficiency. There were no differences in the odds of developing grade 2 or more renal insufficiency when factors of age, primary tumor (NSCLC vs. other), steroid use and trial status were assessed (supplementary data not shown, available upon request). Patients with RCC had higher odds of experiencing grade 2 or more kidney injury than patients with other primary tumor types (adjusted $p=0.025$ ) (Table III). The majority of patients with documented kidney injury suffered transient rise in creatinine during treatment, which might be attributed to poor oral intake or possibly due to nephrotoxicity from concomitant drugs. However, four 
Table III. Univariate and multivariate logistic regression analyses of factors associated with grade 2 or more toxicity.

\begin{tabular}{|c|c|c|c|c|c|c|}
\hline Toxicity & Factor & Subgroup & Unadjusted OR (95\% CI) & $p$-Value & Adjusted OR (95\% CI) & $p$-Value \\
\hline \multirow[t]{7}{*}{ Pneumonitis } & Age, years & & $0.99(0.96-1.02)$ & 0.559 & $1.00(0.96-1.04)$ & 0.879 \\
\hline & Lung disease & No & Ref. & & Ref. & \\
\hline & & Yes & $0.64(0.22-2.10)$ & 0.424 & $0.65(0.20-2.41)$ & 0.487 \\
\hline & Steroid use & No & Ref. & & Ref. & \\
\hline & & Yes & $4.16(1.52-13.34)$ & 0.009 & $4.19(1.53-13.50)$ & 0.009 \\
\hline & Clinical trial & Off & Ref. & & Ref. & \\
\hline & & On & $1.16(0.41-3.02)$ & 0.771 & $1.10(0.37-3.10)$ & 0.854 \\
\hline \multirow[t]{7}{*}{ Transaminitis } & Age, years & & $1.00(0.97-1.03)$ & 0.887 & $1.00(0.97-1.02)$ & 0.743 \\
\hline & Liver metastasis & No & Ref. & & Ref. & \\
\hline & & Yes & $2.61(1.20-5.68)$ & 0.015 & $2.64(1.19-5.82)$ & 0.016 \\
\hline & Steroid use & No & Ref. & & Ref. & \\
\hline & & Yes & $0.76(0.35-1.60)$ & 0.473 & $0.83(0.38-1.77)$ & 0.627 \\
\hline & Clinical trial & Off & Ref. & & Ref. & \\
\hline & & On & $1.06(0.47-2.30)$ & 0.883 & $1.13(0.48-2.55)$ & 0.776 \\
\hline \multirow[t]{7}{*}{ Kidney injury } & Age, years & & $1.03(1.00-1.06)$ & 0.111 & $1.03(1.00-1.07)$ & 0.072 \\
\hline & Primary tumor & $\mathrm{RCC}$ & Ref. & & Ref. & \\
\hline & & Other & $0.37(0.16-0.90)$ & 0.025 & $0.37(0.15-0.90)$ & 0.025 \\
\hline & Steroid use & No & Ref. & & Ref. & \\
\hline & & Yes & $0.85(0.38-1.88)$ & 0.686 & $0.87(0.38-1.96)$ & 0.731 \\
\hline & Clinical trial & Off & Ref. & & Ref. & \\
\hline & & On & $1.24(0.53-2.80)$ & 0.612 & $1.51(0.61-3.64)$ & 0.365 \\
\hline \multirow[t]{7}{*}{ Hypothyroidism } & Age, years & & $1.01(0.98-1.04)$ & 0.526 & $1.03(1.00-1.07)$ & 0.078 \\
\hline & Primary tumor & HL/HNSCC & Ref. & & Ref. & \\
\hline & & Other & $0.40(0.16-1.00)$ & 0.045 & $0.17(0.05-0.57)$ & 0.005 \\
\hline & Steroid use & No & Ref. & & Ref. & \\
\hline & & Yes & $0.62(0.28-1.34)$ & 0.225 & $0.61(0.27-1.36)$ & 0.233 \\
\hline & Clinical trial & Off & Ref. & & Ref. & \\
\hline & & On & $0.76(0.32-1.71)$ & 0.519 & $0.58(0.21-1.47)$ & 0.270 \\
\hline
\end{tabular}

CI, Confidence intervaI; HL, Hodgkin's lymphoma; HNSCC, Head and neck squamous cell carcinoma; OR, odds ratio; RCC, renal cell carcinoma.

patients received steroids with documentation of immunemediated nephritis as the indication, suggesting immunerelated injury.

Hypothyroidism. Those with primary NSCLC had higher odds (adjusted $p=0.022$ ) of developing grade 2 or more hypothyroidism when factors of age, primary tumor, steroid use and trial status were assessed (supplementary data not shown, available upon request). When the primary tumor site was analyzed, patients with HL and HNSCC had higher odds of experiencing grade 2 or more hypothyroidism (adjusted $p=0.005$ ) (Table III).

Transaminitis. There were no differences in the odds of developing grade 2 or more transaminitis when factors of age, combination therapy, primary tumor (NSCLC vs. others), and trial status were assessed (supplementary data not shown, available upon request). The majority of patients with documented transaminitis suffered transient rise in hepatic function tests during treatment, which might be attributed to worsening liver metastasis or possibly due to hepatotoxicity from concomitant drugs. However, five patients received steroids with documentation of immune-mediated transaminitis as the indication, suggesting immune-related injury.

Pneumonitis. There was no correlation between odds of developing grade 2 or more pneumonitis when comparing the primary tumor site of NSCLC versus other primary cancer (adjusted $p=0.999$ ) (supplementary data not shown, available upon request).

Colitis/diarrhea. Those with primary NSCLC had higher odds (adjusted $p=0.030$ ) of developing grade 2 or more colitis when factors of age, primary tumor, steroid use and trial status were assessed (supplementary data not shown, available upon request).

Survival. Patients with primary NSCLC had worse OS (Table IV). Patients with primary NSCLC had worse OS regardless of the type of toxicities experienced, which remained significant even after being adjusted for other parameters of age, clinical trial status, steroid use and grades of toxicities with one exception of hypothyroidism (supplementary data not shown, available upon request). 
Table IV. Univariate and multivariate Cox regression analyses of factors associated with overall survival.

\begin{tabular}{lcccc}
\hline Factor & $\begin{array}{c}\text { Unadjusted } \\
\text { HR }(95 \% \mathrm{CI})\end{array}$ & $p$-Value & $\begin{array}{c}\text { Adjusted HR } \\
(95 \% \mathrm{CI})\end{array}$ & $p$-Value \\
\hline Age, years & & & & \\
& $1.02(1.00-1.03)$ & 0.047 & $1.01(0.99-1.03)$ & 0.441 \\
Clinical trial & Ref. & & Ref. & \\
Off & $0.57(0.33-0.98)$ & 0.044 & $0.73(0.41-1.30)$ & 0.282 \\
$\begin{array}{l}\text { On } \\
\text { Primary tumor } \\
\text { NSCLC }\end{array}$ & Ref. & & Ref. & \\
$\begin{array}{l}\text { Other } \\
\text { Steroid use } \\
\text { No } \\
\text { Yes }\end{array}$ & $0.43(0.27-0.69)$ & 0.001 & $0.48(0.29-0.81)$ & 0.005 \\
\hline
\end{tabular}

CI: Confidence intervaI; HR: hazard ratio; NSCLC, non-small cell lung cancer.

Patients whose primary cancer was NSCLC had higher risk of death with pneumonitis than those whose primary cancer was not NSCLC (unadjusted $p=0.001$ ), and it remained significant after adjusting for age, clinical trial status, grade, and steroid use (adjusted $p=0.005$ ) (supplementary data not shown, available upon request).

Similarly, when pneumonitis occurred in patients with lung disease, which in this study was defined by having primary or metastatic tumor in the lung parenchyma, the OS was significantly worse (unadjusted $p=0.002$ ) and remained significant (adjusted $p=0.006$ ) even after adjusting for age, clinical trial status, toxicity grade, and steroid use (Table V).

Figure 1 shows the Kaplan-Meier curves of OS for group 1 and group 2. The median OS was 47.4 months $(95 \% \mathrm{CI}=15.4$ months-not reached) and 38.7 months (95\% CI=13.2 monthsnot reached) for groups 1 and 2, respectively. The median follow-up time was 25 (95\% CI=19-35.9) months and 27.4 (95\% CI=24.2-34.3) months for groups 1 and 2, respectively.

The duration of PD1 inhibitor use was not significantly associated with the overall number of grade 2 or more AEs ( $p=0.121$, Figure 2A). Figure 2B shows that the duration of PD1 inhibition was not significantly associated with the onset of hypothyroidism $(p=0.635)$, while Figure $2 \mathrm{C}$ shows that the duration of PD1 was significantly associated with the onset pneumonitis $(p=0.007)$.

\section{Discussion}

Immune checkpoint inhibitors are known to cause immunerelated AEs because of abnormal autoimmune response due to hyperactivated T-cells $(14,15)$. Autoimmunity may develop in any tissue. Grade 3 and 4 immune-related AEs are not common, but immune-related AEs of all grades were reported in up to $70 \%$ of patients treated with PD1 or PD-
L1 inhibitors and up to $90 \%$ with cytotoxic T-lymphocyte associated 4 (CTLA4) inhibitors $(16,17)$. Most grade 1 and 2 immune-related AEs can be managed medically, but the unpredictability of its clinical course can be challenging. Rare fatal immune-related AEs have been reported, and retreatment must be considered with caution (18).

Most immune-related AEs seem to occur within 3 to 6 months of starting anti-CTLA-4 (19) or PD1/PD-L1 inhibitors (20). While the risk of immune-related AEs appears to be dose-dependent with CTLA4 antibodies (21), cumulative toxicity with prolonged exposure to anti-PD1 is a theoretical concern (22). Physicians must therefore remain aware of the possibility of delayed effects of immune checkpoint antibodies.

The immune-related AEs reported with use of CTLA4 inhibitors and PD1/PD-L1 inhibitors reportedly differed in frequency. For example, in the Keynote-006 study, which randomized patients with advanced-stage melanoma to ipilimumab or two different dosing schedules of pembrolizumab, hypothyroidism and hyperthyroidism were more frequent in the pembrolizumab-treated groups, whereas colitis and hypophysitis were more frequent in the ipilimumab-treated group. Of note, in this melanoma study, pneumonitis was rare at $0.4 \%$ in both groups (23). In another melanoma trial, CheckMate 067, patients were randomized 1:1:1 to nivolumab monotherapy, ipilimumab monotherapy, or the combination arm of nivolumab and ipilimumab. Not surprisingly, toxicities were more pronounced in the combination arm. For example, grade 3 or 4 diarrhea occurred in $2.2 \%$ of the nivolumab group, $9.3 \%$ of the nivolumab-plusipilimumab group, and $6.1 \%$ of ipilimumab group; and colitis in $0.6 \%, 7.7 \%$, and $8.7 \%$, respectively (24).

Toxicities with PD1 inhibitors may vary with the type of primary tumor being treated. Hypothyroidism occurred more frequently in patients with HNSCC $(>10 \%$ of all grade hypothyroidism reported in CheckMate 141) (25) and HL (12-14\% of all grade hypothyroidism) treated with PD1/PDL1 inhibitors $(9,26,27)$. The frequency of pneumonitis may also vary with the primary tumor, although this remains controversial. While the frequency of pneumonitis was generally low in melanoma studies, it has been reported to be as high as 5\% (any grade pneumonitis) in NSCLC studies (28). On the other hand, Naidoo et al. reported similar incidence of pneumonitis during PD1/PD-L1 inhibitor therapy in patients with melanoma and NSCLC [26 out of $532(5 \%)$ and nine out of $209(4 \%)$, respectively] in a retrospective analysis (29).

Although most prospective trials reported grade 3 or more AEs, we reported grade 2 or more toxicities in our study. While they may not be life-threatening, grade 2 or more AEs do require careful management (13). In addition, our frequency of grade 3 or more AEs was low, making it difficult to perform a meaningful statistical analysis. 
Table V. Univariate and multivariate Cox regression analyses of factors associated with overall survival by toxicity.

\begin{tabular}{|c|c|c|c|c|c|c|}
\hline Toxicity & Factor & Subgroup & Unadjusted OR $(95 \% \mathrm{CI})$ & $p$-Value & Adjusted OR (95\% CI) & $p$-Value \\
\hline \multirow[t]{9}{*}{ Pneumonitis } & Age, years & & $1.02(1.00-1.03)$ & 0.047 & $1.00(0.99-1.02)$ & 0.618 \\
\hline & Clinical trial & Off & Ref. & & Ref. & \\
\hline & & On & $0.57(0.33-0.98)$ & 0.044 & $0.68(0.39-1.18)$ & 0.167 \\
\hline & Lung disease & No & Ref. & & Ref. & \\
\hline & & Yes & $3.75(1.62-8.68)$ & 0.002 & $3.36(1.41-7.98)$ & 0.006 \\
\hline & Steroid use & No & Ref. & & Ref. & \\
\hline & & Yes & $0.88(0.55-1.40)$ & 0.590 & $0.79(0.49-1.28)$ & 0.338 \\
\hline & Toxicity & Grade $0-1$ & Ref. & & Ref. & \\
\hline & & Grade $\geq 2$ & $1.23(0.63-2.40)$ & 0.543 & $1.32(0.66-2.64)$ & 0.427 \\
\hline \multirow[t]{9}{*}{ Transaminitis } & Age, years & & $1.02(1.00-1.03)$ & 0.047 & $1.01(1.00-1.03)$ & 0.147 \\
\hline & Clinical trial & Off & Ref. & & Ref. & \\
\hline & & On & $0.57(0.33-0.98)$ & 0.044 & $0.66(0.37-1.17)$ & 0.159 \\
\hline & Liver mets & No & Ref. & & Ref. & \\
\hline & & Yes & $1.12(0.68-1.87)$ & 0.653 & $0.95(0.55-1.65)$ & 0.869 \\
\hline & Steroid use & No & Ref. & & Ref. & \\
\hline & & Yes & $0.88(0.55-1.40)$ & 0.590 & $0.89(0.55-1.44)$ & 0.639 \\
\hline & Toxicity & Grade $0-1$ & Ref. & & Ref. & \\
\hline & & Grade $\geq 2$ & $1.27(0.74-2.20)$ & 0.384 & $1.29(0.72-2.29)$ & 0.391 \\
\hline \multirow[t]{9}{*}{ Kidney injury } & Age, years & & $1.02(1.00-1.03)$ & 0.047 & $1.01(0.99-1.03)$ & 0.188 \\
\hline & Clinical trial & Off & Ref. & & Ref. & \\
\hline & & On & $0.57(0.33-0.98)$ & 0.044 & $0.65(0.36-1.15)$ & 0.137 \\
\hline & Primary tumor & $\mathrm{RCC}$ & Ref. & & Ref. & \\
\hline & & Other & $1.08(0.62-1.87)$ & 0.779 & $1.04(0.59-1.83)$ & 0.891 \\
\hline & Steroid use & No & Ref. & & Ref. & \\
\hline & & Yes & $0.88(0.55-1.40)$ & 0.590 & $0.88(0.55-1.41)$ & 0.601 \\
\hline & Toxicity & Grade $0-1$ & Ref. & & Ref. & \\
\hline & & Grade $\geq 2$ & $1.16(0.65-2.08)$ & 0.620 & $1.11(0.60-2.04)$ & 0.739 \\
\hline \multirow[t]{9}{*}{ Hypothyroidism } & Age, years & & $1.02(1.00-1.03)$ & 0.047 & $1.01(0.99-1.03)$ & 0.389 \\
\hline & Clinical trial & Off & Ref. & & Ref. & \\
\hline & & On & $0.57(0.33-0.98)$ & 0.044 & $0.83(0.45-1.53)$ & 0.546 \\
\hline & Primary tumor & HL/HNSCC & Ref. & & Ref. & \\
\hline & & Other & $3.40(1.36-8.47)$ & 0.009 & $2.29(0.82-6.34)$ & 0.112 \\
\hline & Steroid use & No & Ref. & & Ref. & \\
\hline & & Yes & $0.88(0.55-1.40)$ & 0.590 & $1.03(0.61-1.74)$ & 0.924 \\
\hline & Toxicity & Grade $0-1$ & Ref. & & Ref. & \\
\hline & & Grade $\geq 2$ & $1.02(0.56-1.87)$ & 0.948 & $1.05(0.57-1.94)$ & 0.883 \\
\hline
\end{tabular}

CI, Confidence intervaI; HL, Hodgkin's lymphoma; HNSCC, Head and neck squamous cell carcinoma; OR, odds ratio; RCC, renal cell carcinoma.

In our data set, patients with HL and HNSCC had higher odds of experiencing grade 2 or more hypothyroidism (adjusted $p=0.005$ ) after adjusting for age, trial status and steroid use. This is consistent with previous studies $(7,9,10)$. This could be related to previous radiation exposure to the thyroid; 11 out of 18 patients with HL had received previous radiation to the neck/mediastinum area, two out of 18 had total body irradiation, and eight out of nine patients with HNSCC had previous radiation in the head and neck area.

Patients with RCC had higher odds of experiencing grade 2 or more kidney injury than patients with other primary types (adjusted $p=0.025$ ). This is consistent with what has been reported from nivolumab prescribing information. Grade 1-4 increased creatinine was seen in $42 \%$ of the nivolumab arm in the CheckMate025 study (comparing nivolumab vs. everolimus in RCC) (7), whereas it was only found in $18 \%$ in the nivolumab arm of the CheckMate017 and 057 studies (comparing nivolumab vs. docetaxel in NSCLC) $(3,25,30)$. While the majority of patients in our study with documented kidney injury suffered transient rise in creatinine during treatment, which could be attributed to poor oral intake or nephrotoxicity from other concomitant drugs, four patients received steroids with documentation of immune-mediated nephritis as the indication, suggesting immune-related injury. At $2 \%$ (four out of 168), the percentage of all grade immunerelated nephritis which was seen in our study is similar to $1.2 \%$ which was reported in the nivolumab prescribing information (30). Autoimmune nephritis secondary to antitumor immune response in the renal parenchyma should always be considered as one of the differentials (31) especially 


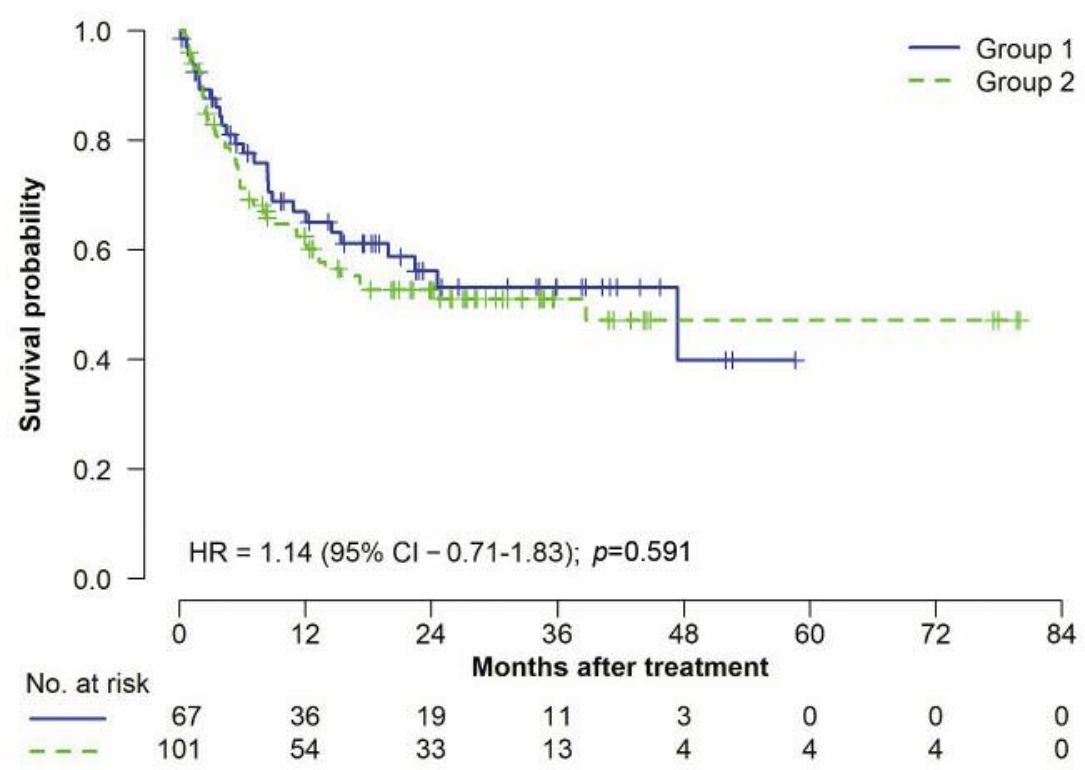

Figure 1. Kaplan-Meier curves of overall survival according to severity of adverse events (AEs). Groups 1 and 2 represent patients who experienced no more than grade $1 \mathrm{AEs}$ and those who experienced at least one grade $2 \mathrm{AE}$, respectively. The median overall survival for groups 1 and 2 was 47.4 months [95\% confidence interval $(C I)=15.4$ months to not reached] and 38.7 months (95\% CI=13.2 months to not reached), respectively. The median follow-up calculated using the reverse Kaplan-Meier estimator was 25 (95\% CI=19 to 35.9) months and 27.4 (95\% CI=24.2-34.3) months, respectively.
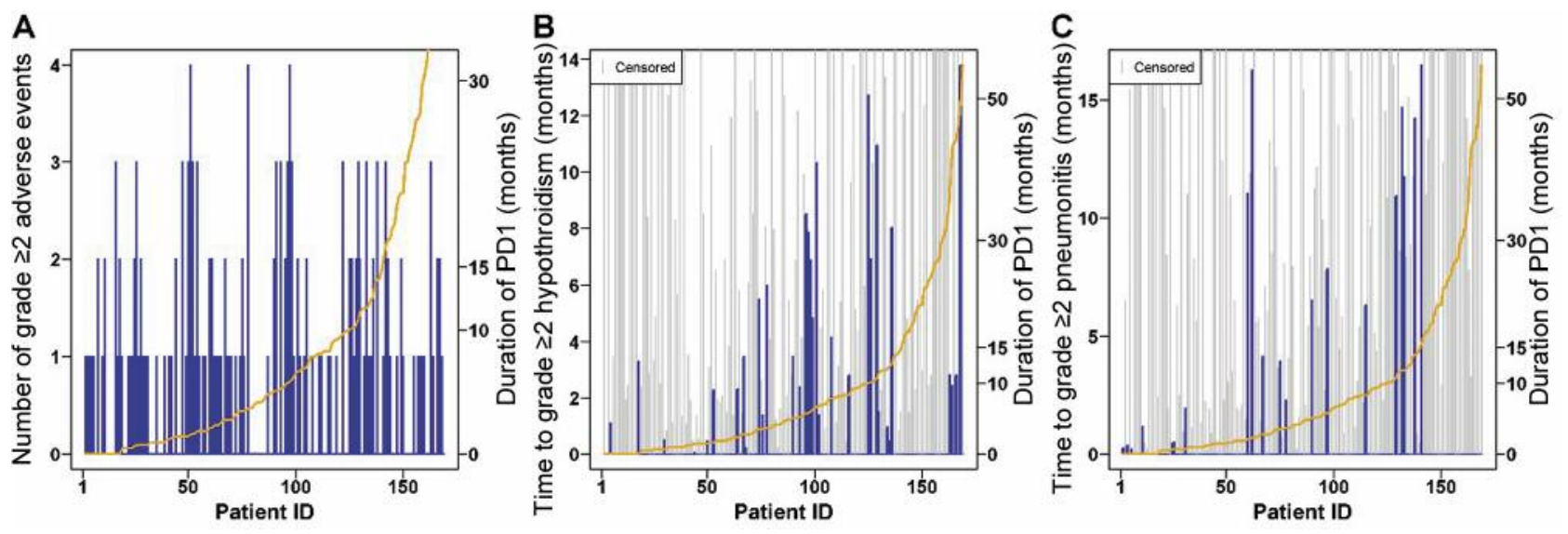

Figure 2. The association between the duration of programmed cell death-1 (PD1) inhibitor use and the number of grade 2 or more adverse events $(A)$, time to hypothyroidism $(B)$ and time to pneumonitis $(C)$. Patients who died without hypothyroidism/pneumonitis or did not experience hypothyroidism/pneumonitis until the last follow-up were censored. $p$-Values: A: $p=0.121$ (Kruskal-Wallis test); B: $p=0.6$ (log-rank test); $C: p=0.007$ (log-rank test).

in those with RCC as these patients may have had previous nephrectomy. Indeed, in our study population, most patients with RCC had undergone nephrectomy ( $\mathrm{n}=41$ : 34 radical nephrectomy, two partial nephrectomy), which may have made them more susceptible to acute kidney injury.

The odds of developing grade 2 or more pneumonitis was not increased in patients with NSCLC, which may have been related to the fact that pneumonitis events were high across all tumor types, with 10 patients $(6 \%)$ with grade 2 , nine (5\%) with grade 3 and one (1\%) with grade 4 in our study. Pneumonitis, when occurring in patients with lung disease, which in this study was defined as having a primary or metastatic tumor in the lung parenchyma, led to significantly worse OS. This may be attributed to underlying emphysematous disease from smoking and possibly due to previous thoracic surgery/radiation, making such patients 
vulnerable to the serious consequences of further inflammation in the lungs. In our observation, the frequency of pneumonitis was higher than in a recent meta-analysis of 20 studies which reported an overall incidence of $2.7 \%$ with PD1 inhibition (32). We initially thought that this was due to the high number of patients with NSCLC in our study (87 out of 168). However, the odds of developing grade 2 or more pneumonitis was not increased in patients with NSCLC. The increased frequency of pneumonitis in this study likely represents over-reporting, as investigators in this study were instructed to capture pneumonitis events not only through the electronic notes of the treating physicians, but also through computed tomographic scan reports documenting findings consistent with pneumonitis when the treating physicians' notes mentioned the possibility of "immune-response" or "inflammatory-response" even if the term pneumonitis was not used. Fifteen out of 20 patients with grade 2 or more pneumonitis received steroids. In our study, the duration of PD1 therapy was significantly associated with onset of pneumonitis $(p=0.007$, Figure 2$)$ which is consistent with previous reports (33), although early onset of pneumonitis has been reported with combination therapy (34) and higher rates of pneumonitis in treatmentnaïve patients than in previously treated patients have been shown in a previous meta-analysis (35).

This study has limitations: it was retrospective in nature, and included different tumor types and different treatment patterns, with almost one-third of the patient population being treated on clinical trials. Although the heterogeneity of the study population in some ways limits the analysis, we were able to compare the AEs (including potential immunerelated AEs) between various tumor types and provide new findings.

Early diagnosis and treatment of any AEs, especially immune-related, is the key to successful outcomes. All patients receiving PD1 inhibitor agents should routinely have thyroid function studies, complete blood counts, and liver function tests while on PD1/PD-L1 inhibitors, at intervals of 6 to 12 weeks for the first 6 months after finishing treatment. Adrenocorticotropic hormone, cortisol, and in men, testosterone, should also be checked in patients who develop fatigue or nonspecific symptoms. Follow-up testing may need to be increased in frequency based on individual response and AEs (36). Corticosteroids have been the mainstay of treatment for immune-related AEs. As with all AEs, careful clinical assessment and a case-by-case approach is imperative. While there are concerns regarding the immunosuppressive nature of corticosteroids having negative effects on T-cell function (37), it is reassuring to see emerging data demonstrating that on-treatment corticosteroid use for immune-related AE management does not seem to negatively impact the efficacy of PD1 treatment (38-40). Therefore, early recognition and early initiation of corticosteroids is recommended for grade 3 and higher immune-related AEs and in some of grade 2 or more such as pneumonitis (12).

\section{Conclusion}

The site of primary tumor or metastasis may help predict the most common AEs in patients treated with PD1 inhibitors. Patients with RCC had higher odds of experiencing grade 2 or more kidney injury while on therapy, whereas those with HL and HNSCC had higher odds of experiencing grade 2 or more hypothyroidism. The odds of developing grade 2 or more pneumonitis were not increased in patients with NSCLC, although pneumonitis was associated with worse survival when occurring in those with primary NSCLC and those with lung metastases.

\section{Funding}

This study did not receive any funding.

\section{Availability of Data and materials}

The datasets during and/or analyzed during study will be made available from the corresponding Author upon reasonable request and approval from the IRB.

\section{Conflicts of Interest}

The Authors declare no competing interest related to this study.

\section{Acknowledgements}

The Authors wish to thank the patients and the families who were treated at our site. Preliminary data were presented at the 2017 ASCO Annual Meeting as an electronic publication. Presented in part at the 2018 Immuno-Oncology Young Investigators' Forum by The University of Texas MD Anderson Cancer Center and Creative Educational Concepts, Inc. (CEC) in collaboration with the Society for Immunotherapy of Cancer.

\section{References}

1 Wolchok JD, Chiarion-Sileni V, Gonzalez R, Rutkowski P, Grob JJ, Cowey CL, Lao CD, Wagstaff J, Schadendorf D, Ferrucci PF, Smylie M, Dummer R, Hogg D, Haanen J, Carlino MS, Bechter O, Maio M, Marquez-Rodas I, Guidoboni M, McArthur G, Lebbé C, Ascierto PA, Long GV, Cebon J, Sosman J, Postow MA, Callahan MK, Walker D, Rollin L, Bhore R, Hodi FS and Larkin $\mathrm{J}$ : Overall survival with combined nivolumab and ipilimumab in advanced melanoma. N Engl J Med 377(14): 1345-1356, 2017.

2 Schachter J, Ribas A, Long GV, Arance A, Grob JJ, Mortier L, Daud A, Carlino MS, McNeil C, Lotem M, Larkin J, Lorigan P, Neyns B, Blank C, Petrella TM, Hamd O, Zhou H, Ebbinghaus $\mathrm{S}$, Ibrahim $\mathrm{N}$ and Robert $\mathrm{C}$ : Pembrolizumab versus ipilimumab for advanced melanoma: final overall survival results of a multicenter, randomized, open-label phase study (KEYNOTE006). Lancet 390(10105): 1853-1862, 2017. 
3 Horn L, Spigel DR, Vokes EE, Holgado E, Ready N, Steins M, Poddubskaya E, Borghaei H, Felip E, Paz-Ares L, Pluzanski A, Reckamp KL, Burgio MA, Kohlhäeufl M, Waterhouse D, Barlesi F, Antonia S, Arrieta O, Fayette J, Crinò L, Rizvi N, Reck M, Hellmann MD, Geese WJ, Li A, Blackwood-Chirchir A, Healey $\mathrm{D}$, Brahmer J and Eberhardt WEE: Nivolumab versus docetaxel in previously treated patients with advanced non-small-cell lung cancer: Two-year outcomes from two randomized, open-label, phase III trials (CheckMate 017 and CheckMate 057). J Clin Oncol 35(35): 3924-3933, 2017.

4 Langer CJ, Gadgeel SM, Borghaei H, Papadimitrakopoulou VA, Patnaik A, Powell SF, Gentzler RD, Martins RG, Stevenson JP, Jalal SI, Panwalkar A, Yang JC, Gubens M, Sequist LV, Awad MM, Fiore J, Ge Y, Raftopoulos H, Gandhi L; KEYNOTE-021 investigators. Carboplatin and pemetrexed with or without pembrolizumab for advanced, non-squamous non-small-cell lung cancer: a randomized, phase 2 cohort of the open-label KEYNOTE-021 study. Lancet Oncol 17(11): 1497-1508, 2016.

5 Rittmeyer A, Barlesi F, Waterkamp D, Park K, Ciardiello F, von Pawel J, Gadgeel SM, Hida T, Kowalski DM, Dols MC, Cortinovis DL, Leach J, Polikoff J, Barrios C, Kabbinavar F, Frontera OA, De Marinis F, Turna H, Lee JS, Ballinger M, Kowanetz M, He P, Chen DS, Sandler A, Gandara DR, OAK Study Group. Atezolizumab versus docetaxel in patients with previously treated non-small-cell lung cancer (OAK): A phase 3 , open-label, multicenter randomized controlled trial. Lancet 389(10066): 255-265, 2017.

6 Seiwert TY, Burtness B, Mehra R, Weiss J, Berger R, Eder JP, Heath K, McClanahan T, Lunceford J, Gause C, Cheng JD and Chow LQ: Safety and clinical activity of pembrolizumab for treatment of recurrent or metastatic squamous cell carcinoma of the head and neck (KEYNOTE-012): An open-label, multicentre, phase 1b trial. Lancet OncoI 17: 956-965, 2016.

7 Motzer RJ, Escudier B, McDermott DF, George S, Hammers HJ, Srinivas S, Tykodi SS, Sosman JA, Procopio G, Plimack ER, Castellano D, Choueiri TK, Gurney H, Donskov F, Bono P, Wagstaff J, Gauler TC, Ueda T, Tomita Y, Schutz FA, Kollmannsberger C, Larkin J, Ravaud A, Simon JS, Xu LA, Waxman IM, Sharma P; CheckMate 025 Investigators: Nivolumab versus everolimus in advanced renal-cell carcinoma. N Engl J Med 373: 1803-1813, 2015.

8 Balar AV, Galsky MD, Rosenberg JE, Powles T, Petrylak DP, Bellmunt J, Loriot Y, Necchi A, Hoffman-Censits J, PerezGarcia JL, Dawson NA, van der Heijden MS, Dreicer R, Srinivas S, Retz MM, Joseph RW, Drakaki A, Vaishampayan UN, Sridhar SS, Quinn DI, Durán I, Shaffer DR, Eigl BJ, Grivas PD, Yu EY, Li S, Kadel EE 3rd, Boyd Z, Bourgon R, Hege PS, Mariathasan S, Thåström A, Abidoye OO, Fine GD, Bajorin DF; IMvigor210 Study Group: Atezolizumab as first-line treatment in cisplatin-ineligible patients with locally advanced metastatic urothelial carcinoma: A single-arm, multicenter, phase 2 trial. Lancet 389(10064): 67-76, 2017.

9 Ansell SM, Lesokhin AM, Borrello I, Halwani A, Scott EC, Gutierrez M, Schuster SJ, Millenson MM, Cattry D, Freeman GJ, Rodig SJ, Chapuy B, Ligon AH, Zhu L, Grosso JF, Kim SY, Timmerman JM, Shipp MA and Armand P: PD-1 blockade with nivolumab in relapsed or refractory Hodgkin's lymphoma. N Engl J Med 372: 311-319, 2015.

10 https://www.accessdata.fda.gov/drugsatfda_docs/label/2017/ 125554s055lbl.pdf (last accessed 9/10/2018).
11 https://www.accessdata.fda.gov/drugsatfda_docs/label/2016/ 125514s012lbl.pdf (last accessed 9/10/2018).

12 Brahmer JR, Lachetti C, Schneider BJ, Atkins MB, Brassil KJ, Catarino JM,Chau I, Ernstoff MS, Garner JM, Ginex P, Hallmeyer S, Holter Chakrabarty J, Leighl NB, Mammen JS, McDermott DF, Naing A, Nastoupil LJ, Phillips T, Porter LD, Puzanov I, Reichner CA, Santomasso BD, Seigel C, Spira A, Suarez-Almazor ME, Wang Y, Weber JS, Wolchok JD, Thompson JA; National Comprehensive Cancer Network: Management of immune-related adverse events in patients with immune checkpoint inhibitor therapy: American Society of Clinical Oncology Clinical Practice Guideline. J Clin Oncol 36(17): 1714-1768, 2017.

13 Common Terminology Criteria for Adverse Events (CTCAE) Version $4.0 \mathrm{https}: / / \mathrm{www}$. eortc.be/services/doc/ctc/CTCAE_4.03_ 2010-06-14_QuickReference_5x7.pdf (last accessed 9/10/2018).

14 Hodi FS, Mihm MC, Soiffer RJ, Haluska FG, Butler M, Seiden MV, Davis T, Henry-Spires R, MacRae S, Willman A, Padera R, Jaklitsch MT, Shankar S, Chen TC, Korman A, Allison JP and Dranoff G: Biologic activity of cytotoxic T lymphocyteassociated antigen 4 antibody blockade in previously vaccinated metastatic melanoma and ovarian carcinoma patients. Proc Natl Acad Sci USA 100: 4712-4717, 2003.

15 Johnson RL, Lutzky J, Chodhry A and Barkin JS: Cytotoxic Tlymphocyte-associated antigen 4 antibody-induced colitis and its management with infliximab. Dig Dis Sci 54: 2538-2540, 2009.

16 Topalian SL, Hodi FS, Brahmer JR, Gettinger SN, Smith DC, McDermott DF, Powderly JD, Carvajal RD, Sosman JA, Atkins MB, Leming PD, Spigel DR, Antonia SJ, Horn L, Drake CG, Pardoll DM, Chen L, Sharfman WH, Anders RA, Taube JM, McMiller TL, Xu H, Korman AJ, Jure-Kunkel M, Agrawal S, McDonald D, Kollia GD, Gupta A, Wigginton JM and Sznol M: Safety, activity, and immune correlates of anti-PD-1 antibody in cancer. N Engl J Med 366: 2443-2454, 2012.

17 Brahmer JR, Tykodi SS, Chow LQ, Hwu WJ, Topalian SL, Hwu P, Drake CG, Camacho LH, Kauh J, Odunsi K, Pitot HC, Hamid O, Bhatia S, Martins R, Eaton K, Chen S, Salay TM, Alaparthy S, Grosso JF, Korman AJ, Parker SM, Agrawal S, Goldberg SM, Padroll DM, Gupta A and Wigginton JM: Safety and activity of anti-PD-L1 antibody in patients with advanced cancer. N Engl J Med 366: 2455-2465, 2012.

18 Santini FC, Rizvi H, Plodkowski AJ, Ni A, Lacouture ME, Gamnarin-Gelwan M, Wilkins O, Panora E, Halpenny DF, Long NM, Kris MG, Rudin CM, Chaft JE and Hellmann MD: Safety and efficacy of re-treating with immunotherapy after immunerelated adverse events in patients with NSCLC: Cancer Immunol Res 6(9): 1093-1099, 2018.

19 Weber JS, Dummer R, de Pril V, Lebbé C, Hodi FS, MDX01020 Investigators. Patterns of onset and resolution of immune related adverse events of special interest with ipilimumab: detailed safety analysis from a phase 3 trial in patients with advanced melanoma. Cancer 119: 1675-1682, 2013.

20 Topalian SL, Sznol M, McDermott DF, Kluger HM, Carvajal RD, Sharfman WH, Brahmer JR, Lawrence DP, Atkins MB, Powderly JD, Leming PD, Lipson EJ, Puzanov I, Smith DC, Taube JM, Wigginton JM, Kollia GD, Gupta A, Pardoll DM, Sosman JA and Hodi FS: Survival, durable tumor remission, and long-term safety in patients with advanced melanoma receiving nivolumab. J Clin Oncol 32: 1020-1030, 2014. 
21 Maker AV, Yang JC, Sherry RM, Topalian SL, Kammula US, Royal RE, Hughes M, Yellin MJ, Haworth LR, Levy C, Allen T, Mavroukakis SA, Attia P and Rosenberg SA: Intrapatient dose escalation of anti-CTLA-4 antibody in patients with metastatic melanoma. J Immunother Hagerstown Md 29: 455-463, 2006.

22 Wolchok JD, Neyns B, Linette G, Negrier S, Lutzky J, Thomas L, Waterfield W, Schadendorf D, Smylie M, Guthrie T Jr., Grobb JJ, Chesney J, Chin K, Chen K, Hoos A, O'Day SJ, Lebbé C: Ipilimumab monotherapy in patients with pretreated advanced melanoma: A randomised, double-blind, multicentre, phase 2, dose-ranging study. Lancet Oncol 11: 155-164, 2010.

23 Robert C, Schachter, J, Long GV, Arance A, Grob JJ, Mortier L, Daud A, Carlino MS, McNeil C, Lotem M, Larkin J, Lorigan P, Neyns B, Blank, CU, Hamid O, Mateus C, Shapira-Frommer R, Kosh M, Zhou H, Ibrahim N, Ebbinghaus S, Ribas A; KEYNOTE-006 investigators: Pembrolizumab versus ipilimumab in advanced melanoma. N Engl J Med 372: 2521-2532, 2015.

24 Larkin J, Chiarion-Sileni V, Gonzalez R, Grobb JJ, Cowey CL, Lao CD, Schadendorf D, Dummer R, Smylie M, Rutkowski P, Ferrucci PF, Hill A, Wagstaff J, Carlino MS, Haanen JB, Maio M, Masquesz-Rodas I, McArthur GA, Ascierto PA, Long GV, Callahan MK, Postow MA, Grossmann K, Sznol M, Dreno B, Bastholt L, Yang A, Rollin LM, Horak C, Hodi FS and Wolchok JD: Combined nivolumab and ipilimumab or monotherapy in untreated melanoma. N Engl J Med 373: 23-34, 2015.

25 Ferris RL, Blumenschein Jr G, Fayette J, Guigay J, Colevas AD, Licitra L, Harrington K, Kasper S, Vokes EE, Even C, Worden F, Saba NF, Iglesias Docampo LC, Haddad R, Rordorf T, Kiyota N, Tahara M, Monga M, Lynch M, Geese WJ, Kopit J, Shaw JW and Gillison ML: Nivolumab for recurrent squamous-cell carcinoma of the head and neck. N Engl J Med 375: 1856-1867, 2016.

26 Chen R, Zinzani PL, Fanale MA, Armand P, Johnson NA, Brice P, Radford J, Ribrag V, Molin D, Vassilakopoulos TP, Tomita A, von Tresckow B, Shipp MA, Zhang Y, Ricart AD, Balakumaran A, Moskowitz CH; KEYNOTE-087: Phase II Study of the efficacy and safety of pembrolizumab for relapsed/refractory classic Hodgkin lymphoma. J Clin Oncol 35: 2125-2132, 2017.

27 Armand P, Engert A, Younes A, Fanale M, Santoro A, Zinzani PL, Timmerman JM, Collins GP, Ramchandren R, Cohen JB, De Boer JP, Kuruvilla J, Savage KJ, Trneny M, Shipp MA, Kato K, Sumbul A, Farsaci B and Ansell SM: Nivolumab for relapsed/refractory classsic Hodgkin lymphoma after failure of autologous hematopoietic cell transplantation: Extended followup of the multicohort single-arm phase II CheckMate 205 trial. J Clin Oncol 36: 1428-1439, 2018.

28 Brahmer J, Reckamp KL, Baas P, Crinò L, Eberhardt WE, Poddubskaya E, Antonia S, Pluzanski A, Vokes EE, Holgado E, Waterhouse D, Ready N, Gainor J, Arén Frontera O, Havel L, Steins M, Garassino MC, Aertz JG, Domine M, Paz-Ares L, Reck M, Baudelet C, Harbison CT, Lestini B and Spigel DR: Nivolumab versus docetaxel in advanced squamous-cell nonsmall-cell lung cancer. N Engl J Med 373: 123-135, 2015.

29 Naidoo J, Wang X, Woo KM, Iyriboz T, Halpenny D, Cunningham J, Chaft JE, Segal NH, Callahan MK, Lesokhin AM, Rosenberg J, Voss MH, Rudin CM, Rizvi H, Hou X, Rodriguez K, Albano M, Gordon RA, Leduc C, Rekhtman N, Harris B, Menzies AM, Guminski AD, Carlino MS, Kong BY, Wolchok JD, Postow MA, Long GV and Hellmann MD: Pneumonitis in patients treated with anti-programmed death-1/programmed death ligand 1 therapy. J Clin Oncol 35: 709-717, 2017.
30 Opdivo (nivolumab) [package insert]. Bristol-Myers Squibb, NJ; revised 8/2018. Available at: https://packageinserts.bms.com/ pi/pi_opdivo.pdf. Last accessed on 9/10/2018.

31 Cortazar FB, Marrone KA, Troxell ML, Ralto KM, Hoening MP, Mrahmer JR, Le DT, Lipson EJ, Glezerman IG, Wolchok J, Cornell LD, Feldman P, Stokes MB, Zapata SA, Hodi FS, Ott PA, Yamashita M and Leaf DE: Clinicopathological features of acute kidney injury associated with immune checkpoint inhibitors. Kidney Int 90: 638-647, 2016.

32 Nishio M, Giobbie-Hurder A, Hatabu H, Ramaiya NH and Hodi FS: Incidence of programmed cell death 1 inhibitor-related pneumonitis in patients with advanced cancer: A systematic review and meta-analysis. JAMA Oncol 2: 1607-1616, 2016.

33 Zhang S, Liang F, Zhu J and Chen Q: Risk of pneumonitis associated with programmed cell death 1 inhibitors in cancer patients: A meta-analysis. Mol Cancer Ther 16: 1588-1595, 2017.

34 Chuzi S, Tavora F, Cruz M, Costa R, Chae YK, Carneiro BA and Giles FJ: Clinical features, diagnostic challenges, and management strategies in checkpoint inihibitor-related pneumonitis. Cancer Manag Res 9: 207-213, 2017.

35 Khunger M, Rakshit S, Pasupuleti V, Hernandez AV, Mazzone P, Stevenson J, Pennell NA and Velcheti V: Incidence of pneumonitis with use of programmed death 1 and programmed death-ligand 1 inhibitors in non-small cell lung cancer-a systematic review and meta-analysis of trials. Chest 152: 271-281, 2017.

36 Weber JS, Yang JC, Atkins MB and Disis ML: Toxicities of immunotherapy for the practitioner. J Clin Oncol 33: 2092-2099, 2015.

37 Libert C and Dejager L: How steroids steer T-cells. Cell Reports 7: 938-939, 2014.

38 Postow MA, Sidlow R and Hellmann MD: Immune-related adverse events associated with immune checkpoint blockade. $\mathrm{N}$ Engl J Med 378: 158-168, 2018.

39 Santini FC, Rizvi H, Wilkins O, van Voorthuysen M, Panora E, Halpenny D, Kris MG, Rudin CM, Chaft JE and Hellmann MD: Safety of retreatment with immunotherapy after immune-related toxicity in patients with lung cancers treated with anti-PD(L)-1 therapy. J Clin Oncol 35(suppl): 9012, 2017.

40 Horvat TZ, Adel NG, Dang T-O, Momtaz P, Postow MA, Callahan MK, Carvajal RD, Dickson MA, D'Angelo SP, Woo KM, Panageas KS, Wolchok JD and Chapman PB: Immunerelated adverse events, need for systemic immunosuppression, and effects on survival and time to treatment failure in patients with melanoma treated with ipilimumab at Memorial Sloan Kettering Cancer Center. J Clin Oncol 33: 3193-3198, 2015.
Received October 29, 2018

Revised December 17, 2018

Accepted December 20, 2018 